\title{
Performance Implications of Active Management of Institutional Mutual Funds ${ }^{1}$
}

\section{Ron Bird*^ \\ Paolo Pellizzari** \\ Danny Yeung* \\ The Paul Woolley Centre for the Study of Capital Market Dysfunctionality, UTS Working Paper Series 13}

Draft: September, 2011

\begin{abstract}
Although mutual fund performance has been dissected from almost every angle, very little attention has been paid to the connection between the actual active decisions made by management and the subsequent performance outcomes. In this paper we use information on institutional mutual funds to examine the implications of their active decisions made with respect to active positions, style and cash holdings for the fund's realised alpha, tracking error and information ratio. We identify some areas where the funds across the entire sample have success (active positions, and growth and winning stock divergences) and many others where they fall short (e.g. value and loser stock divergences). We identify that there is significant variation in these findings when we extend our analysis to examine the impact of these active decisions on performance for different styles of funds during periods of weak and strong markets. Value funds prove to be by far the best in the active positions that they make but losing across the board with their style divergences. Finally, we highlight the importance in style choice on the overall performance of a fund and identify the superiority of the value style over its competitors.

* Paul Woolley Centre for the Study of Capital Market Dysfunctionality, University of Technology Sydney

** Department of Applied Mathematics, University of Venice
\end{abstract}

IEL Code: G11, G14, G29

$\wedge$ Corresponding Author: School of Finance and Economics

University of Technology Sydney

PO Box 123 Broadway NSW Australia 2007

Phone: +612 95147716

Email: $\underline{\text { ron.bird@uts.edu.au }}$

\footnotetext{
${ }^{1}$ The authors would like to thank the Paul Woolley Centre at the University of Technology Sydney for providing the funding for this research project.
} 


\section{Performance Implications of Active Management of Institutional Mutual Funds}

An age old question has been why investors are willing to incur costs of about $\$ 100 \mathrm{~B}$. as a result of delegating the majority of their investment funds to active managers (French, 2008). The studies of the performance of active funds are numerous with the general finding being that as a group they underperform their benchmark once account is taken of their management fees and the other incremental costs associated with employing active managers. Of course, the fact that the active management fail to does not outperform does not preclude that many managers will outperform their benchmark over any measurement period. However, most managers are appointed on the basis of their past performance which will only translate into value-adding future outperformance if it proves that there is a high level of persistence in manager performance (Gohal and Wahal, 2008). Again the empirical evidence suggests that there is little persistence in fund performance which adds to the argument that investors would be well advised to delegate the majority of their funds to low costs passive management (Busse et al., 2010).

Previous academic studies have put under the microscope all aspects of US mutual funds including returns, persistence, risk-taking, fees, fund flows and governance. Also they have they have examined the implications of both fund and manager characteristics for fund performance (Golec, 1996; Chevalier and Ellison, 1999; Yan, 2008; Karoui and Meier, 2009). However, there has been surprisingly little analysis that attempts to dissect the ability of managers to add value from the various types of active decisions that they make. Cremers and Petajisto (2009) and Petajisto (2010) developed a measure of the extent to which a fund's actual weights differed from their benchmark weights (which we shall refer to as a fund's active position). They found that the best performance came from the managers who took the largest active positions while the "closet indexers" generated negative after-fees performance. Wermers (2010) introduced a measure of active management that captured three types of style divergences: value/growth, size and momentum. Unlike an earlier study by Brown and Harlow (2001), Wermers found evidence to suggest that those managers willing to contemplate style divergence are most likely to realise superior performance.

The focus of this paper will be on the active decisions made by institutional managers and how they impact on the fund's realised performance (excess returns relative to their benchmark), risk (tracking error to their benchmark) and the manager's information ratio (excess returns divided by tracking error)which is a commonly used measure of his skill. This would appear to be an issue worthy of consideration because of the insights that it will provide into the ability of fund managers as a group and also where one might best look when identifying the better managers. The three types of active decisions that we evaluate are their active position (which is a measure of their aggregate positions against their benchmark), their style divergence (that are measured in the dimensions of value/growth, momentum and size) and their cash holdings (which relates to their market timing). We decompose our findings in a number of dimensions including tracking the relationship between the active decisions made by fund management and fund performance during (i) periods of good and bad market performance, (ii) by the size of the fund, and (iii) by type of investment style pursued by the fund (growth, value and style 
neutral). We will provide evidence on the typical positions made by managers and the implications of these positions for investment outcomes. As such we will provide information relevant to the active /passive debate by way of providing insights as to what forms of active decisions made by fund managers have in the past brought rewards to their clients. Our results highlight numerous instances of manager strength and manager failings that suggest factors that investors should take into account when choosing funds.

The structure of the paper is as follows: Section 1 we provide a more detailed introduction to our study. In Section 2, we outline the data and methodology used in this study. We report our findings in Section 3 while Section 4 provides us with the opportunity to provide a summary of our findings and to suggest some opportunities for further research.

\section{Section 1: Introduction}

Capital markets are replete with managers whose mandates are to get the best investment outcome for their clients. The resulting competition between managers has been considered beneficial largely because of the contribution that it makes to producing efficient pricing in markets. However, the extent and form of the competition that we currently see in (particularly) equity markets has been subject of much discussion in recent years. Initially, the concern was with the ability of active manager to add value for their clients. It was the work of Treynor (1965), Sharpe (1966) and Jensen (1968) that gave credence to the use of passive management as a cost-effective way of gaining market exposure. An equally important challenge for active management has come from the evidence on market anomalies that have evolved over the last $40+$ years. The suggestion is that managers as a group not only fail to make a positive contribution to the wealth of their clients but also seem to be detrimental to the establishment of efficient pricing within markets. Bird et al. (2011A) and Vayanos and Woolley (2008) demonstrate how a combination of costly active managers with performance chasing clients will explain many of the anomalies that have been identified in empirical studies.

There are two important aspects of a funds manager's operations that influence the performance that they achieve: their choice of investment style/process for the fund and the way that the active decisions that they make when implementing that style/process. It has become common practice for each mutual fund to have a particular investment style (e.g. value, growth, market-neutral), defined investment universe, and process for making its active decisions. As a consequence each fund is assigned a benchmark that is representative of both style and process. It is upon this benchmark against which the fund's performance is measured. It is usual to divide the two stages of active management into a stock selection phase and a portfolio construction stage. Stock selection is the process by which a manager determines the extent to which he likes each stock (i.e. his expected alpha for each stock). The manager's alpha estimate will reflect both his expectations relating to the stock's factor exposure (i.e. how well will small cap stocks perform over the time horizon) and to idiosyncratic characteristics of the stock (e.g. the likely success of a new product that it is about to launch). The estimated alphas (i.e. the manager's preferences) then become the 
basis for the portfolio construction phase where the manager determines the weights to be assigned to each stock in the portfolio.

There are many ways that an active manager can attempt to add value and these will vary depending on the mandate of the manager. In this paper we restrict our attention to the management of US domestic equity portfolio in order to reduce the range of value adding options (e.g. excluding the currency decision which would be relevant to active global equity managers). Similar to Cremers and Petajisto (2009), we also assume that we are only dealing with long-only investment in the underlying securities and thus avoid any consideration of derivative securities. This presumption is a fair representation of reality as the typical fund is restricted in the extent to which it can use derivatives within its portfolio.

We use the actual weights assigned to stocks to back out two of the most important active decisions made by a fund: the extent of the active positions taken on individual stocks and the style divergence introduced with respect to several factors/anomalies that have been demonstrated to play an important role in explaining stock returns. The active position is a measure of the extent to which the actual holdings of a fund differ from its benchmark and provides a good measure of the aggressiveness with which the manager implements the style. Cremers and Petajisto (2009) found a positive relationship between active stock positions and performance suggesting that it is the more aggressive managers who will achieve the best performance. One possibility is that a manager will generate a large active position while still investing in stocks whose characteristics are consistent with the manager's investment style. However, another option available to a fund manager in his quest for better fund performance is to introduce stocks into the portfolios that result in factor exposures that are at variance with the fund's style. Therefore, the second measure of active management that we introduce is a measure of style divergence that are based on three individual factors (i.e. value/growth, momentum and size). Wermers (2010) found a positive association between style divergence and performance. A further active decision made by a manager is the amount of cash that they hold in their portfolio as varying their cash holdings is the means by which they implement their market timing decisions. Of the few studies that have examined cash holdings, the empirical evidence on market timing has been mixed. Yan (2006) found no evidence of any relationship between cash holdings and future fund performance. Yet Simutin (2009) showed that funds with high level of excess cash earn outperform its low cash counterparts by a risk adjusted 3\%p.a. In summary, in this paper we evaluate the performance implications of five types of active decisions made by managers: the active position, the value/growth style divergence, the momentum style divergence, the size style divergence, and the level of cash holdings.

The intention of a manager when taking active positions is to produce a return that exceeds the benchmark (the excess returns commonly referred to as the alpha). Of course there is no guarantee that any active decision will lead to a positive outcome so there are risks for investors from appointing active managers. This risk is typically measured by the standard deviation of the excess returns which is commonly referred to as the fund's tracking error. Further, it is also common to use the fund's information ratio, which is calculated by dividing the fund's realised excess return by its tracking error, as a measure 
of the skill of the manager. It is important to recognise that excess returns, tracking error and information ratio are all ex-post measures which are influenced not only of the extent of the active decisions made by the manager but also the manager's skill and the behaviour of the market over the measurement period.

Markets are inherently noisy and hence it has proved difficult to extract a reliable measure of the competence of managers using historical data Our focus in this paper is on providing some insights into their competence by identifying the relationship between decisions over which the managers have control, active position and the three style divergences, cash holdings and the outcomes from their investment decisions, excess returns (alpha), tracking error and information ratio. By examining this relationship between the various active decisions by management and the subsequent investment outcomes, we will obtain insights into the areas where active management has most to offer and so provide an indication as to where to focus when trying to identify managers with the greatest potential to add value. For example, Bird et al. (2011) have identified that ceteris paribus it is the manager's who perceive that they have the greatest potential to add value who will take the largest active positions. If managers are best placed to assess their ability, then the extent of the active positions taken by managers would provide a useful signal to investors attempting to identify managers with the greatest ability.

\section{Section 2: Data and Method}

\section{The Ex-Ante Measures of Active Management}

In this paper we concentrate our attention on three measures of active management: active positions, three different style divergence and cash holdings. Active position is a measure of the extent to which the weights assigned to stocks in the fund's actual portfolio differ from the weights assigned to stocks in the fund's benchmark. If the active positions aggregated to zero, then this would mean that each stocks is assigned its index weighting which of course would be an index fund. Active management involves assigning weights to benchmark stocks that are different to their benchmark weightings and/or investing in stocks that are not in the benchmark. The measure that we use for active position is fundamentally the same as that developed in Cremers and Petajisto (2009). As Cremers and Petajisto pointed out, an active portfolio can be regarded as an investment in the benchmark portfolio plus a long and a short portfolio of equal magnitude. The measure of active management that they propose is equivalent to the proportion that this long/short portfolio represents of the total fund:

$$
\text { Active position }=0.5 \sum_{j=1}^{N} a b s\left(w_{f, j}-w_{i, j}\right)
$$

where the active position is one half of the aggregate of the absolute differences between the actual fund weighting in a particular stock, $w_{f, j}$, and the index weighting for that stock, $w_{i, j}$.

We have quarterly data on fund portfolio holdings from Thomson Reuters and the quarterly portfolio holdings of 18 indexes. Therefore once we have assigned a particular index as the benchmark for a fund, we have all of the information required to calculate the 
fund's active position on a quarterly basis. The benchmark index that Cremers and Petajisto assign to a fund each quarter is that which minimises the fund's active position in that quarter. Although we agree with the principle of determining the appropriate benchmark for a fund based on the index that it most closely tracks, we do not agree with the approach of making this assessment on a quarterly basis and so potentially assigning a different benchmark to a fund each quarter. The approach that we take is similar to that of Cremers and Petajisto to the extent that we determine each quarter the index that most closely tracks each fund's actual portfolio (i.e. the index that gives it the smallest active position). As a consequence over the life of each fund we have a benchmark index assigned each quarter. We then allocate to each fund as its benchmark, that index that was chosen in the greatest number of quarters. In this way, we are able to maintain the principle of choosing the index that is closest to the actual holdings while being able to maintain a single benchmark over the life of the fund.

As discussed previously, it is possible for a fund to have large active positions without introducing any serious departures from the fund's benchmark exposures to value/growth, momentum and size. This would be the case, for example, where the manager of a small cap growth fund restricted his investments to be solely in small cap growth stocks. However, the managers may also have expectations as to the relative performance of various factors over the investments time horizon and wish to build this into their portfolios. For example, a small cap growth manager might expect that large cap stocks will perform best over the investment time horizon and so will tilt his portfolio more towards large cap stocks than one would expect to be the case in a small cap growth portfolio. In this instance, the performance of the fund not only reflects the consequences of the active positions but also the relative performance of the factors behind the style divergences.

We develop a measure of style divergence that reflects the extent to which the style exposures in the fund's portfolio differ from those in the fund's benchmark. The approach that we use to measure style divergence has its foundations in a method used in Wermers (2010). The Wermers measure is based upon each stocks exposure to three factors: value/growth momentum and size. Value/growth is measured by the stocks book-tomarket; momentum by the stock's return over the previous six months and size by the market value of the firm's equity. Every quarter each stock is ranked on the basis of each of these factors and assigned a score from one to five: a one if it ranks in the bottom quintile by that factor, a two if in the second quintile and so on. For example a stock that ranks at the end of a quarter in the top quintile of book-to-market will be assigned a score of five for its value/growth factor.

The style tilt for each stock is then calculated as follows:

Style Divergence in dimension $l=\sum_{j=1}^{N}\left(w_{j}^{a} C_{j}^{l}-w_{j}^{i} C_{j}^{l}\right)$

where $w_{j}^{a}$ is the weight of stock $j$ in the funds portfolio, $w_{j}^{i}$ is the weight of stock $j$ in the fund's benchmark portfolio and $C_{j}^{l}$ is stock j's score in dimension $l$ which is determined as explained above. There are three dimensions (size, value/growth and momentum) and 
each quarter each fund would have a separate style divergence score for each dimension. Unlike the active position score which can only be positive, the style divergences can take on positive or negative values. For example, if the small cap growth fund had a size divergence of +0.4 , then it would have a positive divergence towards size which means that on average its stocks have a higher market cap than do the stocks in the fund's benchmark.

The variable we use for cash holdings is simply the percentage that cash represents of the whole portfolio. The benchmarks applied to the various funds all assume that the assets are fully invested so the percentage fund holdings represent the departure from benchmark. Of course most fund hold some cash for liquidity reasons but our interest is in how they vary these holdings through time in tune with market performance.

\section{The Ex-Post Measures of Fund Performance}

Our interest is on the influence of the active decisions made by fund managers on the performance of the funds. We use three commonly used measures of performance that we calculate on a quarterly basis: excess return (alpha); tracking error; information ratio. The excess returns are calculated relative to the fund's benchmark index, the tracking error is the standard deviation of these excess returns calculated on a daily basis over the quarter while the information ratio is the excess return for the quarter divided by the tracking error of the quarter.

\section{The Data}

Our data set extends from 1999 to 2009 with the majority of the data being collected on a quarterly basis. We restrict our analysis to those mutual funds that have been designated as managing funds from institutional clients. The reason that we do this is because we want to restrict our analysis to managers investing on behalf of more sophisticated clients whose fund choice is more driven by the perceived ability of the managers rather on the advice of third parties whose advice is heavily influenced by the level of commissions paid by the funds (Baker et al., 2009). Most of the data pertaining to the funds is obtained from CRSP Survivor-Bias-Free US Mutual Fund Database with the only exception being the quarterly fund holdings data which is obtained from Thomson Reuters S12 Mutual Fund Holdings. ${ }^{2}$

Central to our analysis are the measures of active management namely Active positions and estimation of Style Divergence. Consistent with Cremers and Petajisto (2009), we estimate the level of active management by comparing the holdings of a mutual fund with the holdings (i.e. composition) of the index. In order to construct the active position, we require both fund holdings data (from Thomson Reuters) and data on index constituents. We collected index compositions data for a total of 18 equity market indexes of which nine belonged to the Russell family (namely the Russell 1000, Russell 2000, and Russell Midcap indexes, plus the value and growth components of each) and sourced from Standard and Poors (the S\&P400, S\&P500 and S\&P600 indexes, plus the value and growth components of each) $)^{3}$.

\footnotetext{
${ }^{2}$ Given that CRSP fund holdings data was only available from 2003, the use of Thomson Reuters S12 Fund holdings data enables us to significantly expand the sample period.

${ }^{3}$ We wish to thank Russells and Stand and Poor for providing this information)
} 
Finally the market and accounting data relating to the stocks that are necessary for the estimation of style divergence are obtained from Compustat. We make use of the CRSP/Compustat Merged Database (CCM) to link the stock data to funds information to perform our analysis.

\section{Sample and Data Selection}

The fund selection process began by collecting actively managed funds over the period from 1999 to 2009 from the universe of CRSP Survivor-Bias-Free US Mutual Fund Database. ${ }^{4}$ From the sample of active funds, we isolated the institutional funds using the institutional fund identifier (inst_fund) from CRSP. ${ }^{5}$ The final sample contains over 1794 actively managed institutional funds for our sample period.

We pooled the quarterly fund information to form our final sample. To be included in the final sample, we require information for the fund for at least 3 quarter. In order to eliminate the impact of outliers, we trimmed the fund fees, excess returns and turnover at the $1^{\text {st }}$ and $99^{\text {th }}$ percentile. After all the restriction, the final sample consists of over 30,000 fund quarter observations over the 1999-2009 period $^{6}$.

\section{The Methodology}

The analysis is conducted by pooled regressions with one of excess returns, tracking error and information ratio as the dependent variable and all of the four measures of active management as the explanatory variables. The excess returns are calculated on a before-fees basis as we wish to capture the impact of active management (the inputs) on performance (the outputs) and do not wish to contaminate the results by the introduction of fees. We also make no adjustment to the excess returns by way, for example, of the Fama and French (1993) three-factor model or the Carhart (1997) four-factor model as again as we are trying to identify how divergences on these factors affect performance, it would not be appropriate to adjust the performance measures in advance for the impact of these factors. Similar to Cremers and Petajisto (2009) we include in most of our regressions, a number of control variables that have been found to have some association with fund performance: turnover, expenses, size, age, past fund flows, past returns and benchmark returns. Our basic regression equation is set out below where the dependent variable is excess returns:

$$
\begin{gathered}
r_{i, t \text { to } t+1}=a_{i}+b_{1, i} A P_{i, t}+b_{2, i} \operatorname{VGST}_{i, t}+b_{3, i} \mathrm{MST}_{i, t}+b_{4, i} S G S T_{i, t}+b_{5, i} \mathrm{CH}_{i, t}+ \\
\sum_{j=1}^{9} C V_{i, j, t}+\text { Year Fixed Effects }+e_{i, t}(1)
\end{gathered}
$$

where $r_{i, t \text { to } t+1}$ is the quarterly return for fund $i$ relative to is benchmark index over the period $t$ to $t=1$;

\footnotetext{
${ }^{4}$ Consistent with other studies in the mutual fund area, we use the funds' strategic objective provided by CRSP to filter our sample. Since CRSP provide several sets of strategic objectives (namely Strategic Insights and Lipper Investment Objectives) and neither set of strategic objectives data covers the entire sample period, we use a combination of Strategic Insights and Lipper Investment Objectives to filter our final sample. We selected funds with the following Lipper Investment objectives: G, GI, LSE, MC, MR and SG. Funds from the Strategic Insights objective codes, we selected AGG, GRI, GRP, ING, SCG and GMC.

${ }^{5}$ Data regarding institutional fund status became from 1999 which is the reason that our study has been confined to the 1999-2009 period.

${ }^{6}$ We started in 1999 as that was the year in which S\&P first provided a separate designation for institutional mutual funds.
} 
$A P_{i}$, is the active position of fund $i$ at time $t$

$V G S T_{i}$, is the value growth style tilt for fund $i$ at time $\mathrm{t}$

$M_{S T} T_{i, t}$ is the momentum style tilt for fund $i$ at time $t$

$S G S T_{i, t}$ is the size style tilt for fund $i$ at time $\mathrm{t}$

$\mathrm{CH}_{i, t}$ is the cash holdings for fund $i$ at time $\mathrm{t}$

$C V_{i, j, t}$ is the value for control variable $j$ for fund $\mathrm{I}$ at time $\mathrm{t}$

This equation is repeated with the fund's tracking error $\left(t_{i, t} t_{t+1}\right)$ and information ratio as the dependent variable. The items of interest in these equations are the coefficients, $b_{1 . .4 \text {, }}$ which provide us with information on the association between the four active decisions and each of the three dependent variables. A positive value for the coefficient on active positions does not suggest that all funds benefit from taking large active positions relative to their benchmark but rather that on average the performance of the funds has benefited from taking larger active positions. A positive value on each of the style divergence (e.g. a divergence towards value stocks) also suggests that on average funds have benefited from a divergence towards value stocks relative to that which is implicit in their benchmark. By implication it also suggests that funds would have been penalised by any tilts in the opposite direction (e.g. towards growth stocks). We question whether it is correct to assume a linear assumption relationship between style tilts and fund performance. In order to test this we expand Equation 1 by the use of dummy variables to allow for the possibility that there is a different relationship between fund performance and negative and positive style tilts divergences. Our findings confirm this to be the case with even some instances where both positive and negative style divergence on the same factor have a positive impact on performance highlighting the potential for managers to generate improved performance by the judicial variation in the style divergences that they introduce to their fund through time.

In all the analysis discussed to date both the measures of active management and of performance are calculated relative to the benchmark index assigned to the fund. By so doing we have abstracted from the fund's style and so evaluated the consequences for the fund's performance of the active decisions taken by the management relative to their assigned benchmark. One value adding decision made by managers that is often ignored in academic studies is the choice of style when the fund is established but not all styles are created equal as is reflected by the fact that some styles outperform other styles over extended time periods. We report in Table 1, the number of funds assigned to each of our 18 indexes and also the annualised performance of each of these indexes which reflects the extent to which some styles have outperformed others over our 11 years sample period. In order to incorporate the style choice as well as the active decisions into our analysis we repeat much of the analysis as discussed above but this time using a well-diversified market index (the Russells 1000) to calculate both the performance of each fund and also the four measures of active management. 


\begin{tabular}{|l|l|l|}
\hline \multicolumn{2}{|l|}{ Table 1 Index benchmark allocations and index returns } \\
\hline $\begin{array}{l}\text { This table shows the distribution of funds to the allotted benchmark indices. We determine each quarter } \\
\text { the index that most closely tracks each fund's actual portfolio (i.e. the index that gives it the smallest } \\
\text { active position). As a consequence over the life of each fund we have a benchmark index assigned each } \\
\text { quarter. The index that was chosen in the greatest number of quarters will be allocated as the fund's } \\
\text { benchmark. Returns are each index's average annualised index returns over the sample period. }\end{array}$ \\
\hline Index Name & Number Of Funds & Return (\%PA) \\
\hline Russell 1000 & 188 & $1.28 \%$ \\
\hline Russell 1000 Growth & 19 & $-1.09 \%$ \\
\hline Russell 1000 Value & 266 & $2.86 \%$ \\
\hline Russell 2000 & 7 & $4.89 \%$ \\
\hline Russell 2000 Growth & 135 & $2.00 \%$ \\
\hline Russell 2000 Value & 86 & $7.09 \%$ \\
\hline Russell Mid & 5 & $5.94 \%$ \\
\hline Russell Mid Growth & 165 & $3.29 \%$ \\
\hline Russell Mid Value & 93 & $6.63 \%$ \\
\hline S\&P 400 & 20 & $6.85 \%$ \\
\hline S\&P 400 Growth & 46 & $5.71 \%$ \\
\hline S\&P 400 Value & 48 & $7.96 \%$ \\
\hline S\&P 500 & 310 & $0.87 \%$ \\
\hline S\&P 500 Growth & 112 & $-0.38 \%$ \\
\hline S\&P 500 Value & 87 & $1.83 \%$ \\
\hline S\&P 600 & 25 & $6.66 \%$ \\
\hline S\&P 600 Growth & 126 & $5.59 \%$ \\
\hline S\&P 600 Value & 56 & $7.00 \%$ \\
\hline
\end{tabular}

\section{Summary Statistics}

We present in Panel A of Table 2 details of the extent of the active decisions by management for the different styles of funds and also under differing prevailing market conditions. First considering the information for all funds, it is apparent that managers in aggregate have a slight divergence towards value stocks and strong momentum stocks, little in the way of a size tilt, and an average cash holding of slightly in excess of $3 \%$. Further, it seems that the managers do not differentiate the extent of their active positions, their size tilt or their level of cash holdings through good and bad market conditions. However, they do slightly reduce their momentum divergence ${ }^{7}$ and their tilt towards value stocks during periods of weak market performance.

\footnotetext{
${ }^{7}$ In subsequent discussion of the momentum divergence, we describe a positive tilt as a divergence towards winning stocks (i.e. stocks that have realised very good performance over the previous six months) and a negative tilt as a tilt towards losing stocks (i.e. stocks that have performed poorly over the previous six months).
} 
Table 2 Mean and Standard Deviations of active management measures

This table details the average and standard deviations of our active management measures for each type of funds. In Panel A, we contrast the fund's average active management measures in different market condition. We define "strong" market conditions as the years: 1999, $2003-2006$ and 2009. The remaining years of the sample are designated as years of "weak" market conditions. In Panel B, we contrast the difference in the level of active management for the smallest and largest tercile of funds. We sort the sample by the fund's tangible net assets. We then classified as "Small" fund for all the funds that falls in the first tercile, while the largest tercile of the sample are designated as the "large" funds. Cash Holdings are reported in decimal form.

\section{Panel A}

\begin{tabular}{|l|l|l|l|l|l|l|l|l|l|l|l|}
\hline \multicolumn{7}{|l|}{ Panel A } \\
\hline \\
\hline
\end{tabular}


Panel B

\begin{tabular}{|l|l|l|l|l|l|l|l|l|l|l|l|}
\hline \multicolumn{7}{|l|}{ ALL FUNDS } \\
\hline
\end{tabular}


There would seem to be some discernible differences between the active management decisions made by the different types of active managers. The growth funds run the highest active positions while the style neutral managers have the lowest positions. Again the growth managers run the largest divergence towards value stocks while the value and style neutral managers if anything run slight growth tilts. All of the managers run divergence towards strong momentum stocks but again it is the growth managers that run the largest style divergence. All styles run significantly larger winner divergence in strong markets than they do in weak markets. There is little difference in the size divergence pursued by the three types of managers, irrespective of the market conditions. On average both the growth and value managers have slightly larger cash holdings than the market-neutral managers with the growth managers being more successful in that they have significantly greater cash holdings in periods of poor market performance. Overall, it would appear that the growth managers are the more aggressive in the active positions that they are willing to take compared to the managers pursuing either of the other two styles of investing.

In Panel B of Table 2, we repeat the same information as in panel A, except this time we divide our sample on the basis fund size rather than market conditions. The major difference being that the smaller funds, irrespective of their style of investing, are much more aggressive than the larger funds in that they take on significantly larger divergence towards both winning stocks (i.e., greater momentum investing) and small cap stocks. In addition, the smaller managers of all types have smaller cash holdings on average than do the larger funds. The funds by size hardly differ in terms of the tilts that they take on value/growth but overall the smaller funds take on slightly larger active positions than is the case with larger managers. The major conclusion that one could draw from the information contained in Panel B is the smaller active funds are more aggressive in implementing their investment style than is the case with the larger funds. Otherwise the information contained in Panel B confirms a number of previous findings such as the growth funds take on the largest tilts towards value stocks and winning stocks.

Section 3: The Findings

We report in Table 3 our findings for the complete sample where we run the regression as set out in Equation 1 but expanded with dummies on the positive and negative style tilts and also with and without the control variables. Overall, it is evident that the active decisions made by management have a significant impact on both a fund's return and its risk characteristics. Our findings confirm those of Cremers and Petajisto (2009) that there is a strong positive relationship between the active position of a fund and its subsequent performance. This confirms our previous discussion where we suggested that the magnitude of the active positions made by a manager might provide a useful indicator as to his ability.

Style divergences can take on either positive or negative values. (i.e. a fund can either overweight or underweight a particular style factor relative to the value for that style factor inherent in its benchmark index). The need to separately examine the positive and negative style divergences is justified by the fact that the coefficients on each prove to be 
different in almost all instances ${ }^{8}$. All of the positive and negative style divergences impact on the excess returns realised by the funds. In the case of the value/growth divergence, the positive tilt away from a fund's benchmark position towards value stocks proves to detract from performance whereas the negative tilt towards growth stocks has a positive on performance negative impact ${ }^{9}$. Similarly there is good and bad news with respect to the momentum tilts with those funds that tilt away from benchmark towards winning stocks (a positive divergence) adding to their performance whereas those that tilt towards losing stocks significantly detract from their performance. With the size divergences, the news is all bad with both the tilts away from benchmark towards both large cap and small cap stocks significantly detracting from performance. Of the six possible style divergences, only those towards positive momentum (winners) and growth stocks would appear to work out well for the funds which suggest that overall they might be benefit more from the active positions that they take rather than the style divergences built into their portfolios. We also report in Table 3 the impact of cash holdings on fund performance and find larger cash holdings translate into greater excess returns. One possible interpretation of this is that fund's are able to use market timing decisions to the betterment of their investment performance.

It is interesting to consider these findings in the light of the information contained in Panels A and B of Table 2. On average the managers, but particularly the growth managers diverged towards value stocks whereas it is the growth divergences that have performed best over our sample period. We see a better outcome when it comes to momentum divergences as all styles of managers run a sizable divergence towards winning stocks which proves to be beneficial to performance over our sample period. On average we find that all styles of managers run a small cap size divergence but this proves ineffectual with respect to its impact on performance. Overall, we have a strong evidence to suggest that active decisions have a significant impact on fund performance but the evidence to date is mixed as to the ability of the managers to exploit these opportunities

We also report in Table 3, the impact of the active decisions on risk as measured by the fund's tracking error relative to its benchmark index. In the absence of any active decisions, the tracking error will be zero and so it comes as no surprise to find that almost all active decisions are positively related to tracking error. This is not the case in every instance as it is possible at the margin for tracking error to either be largely left unchanged or reduced by an active decision. an active decision to either leave tracking error largely unchanged or reduce tracking We have two examples of this as the divergences towards growth and large cap stocks would seem to have a negligible impact on tracking error. However, the active positions taken and the four other style divergences all have make significant contributions to increase the fund's tracking error.

\footnotetext{
${ }^{8}$ We conducted Wald tests on the coefficients on the positive and negative values for each style tilt to test for this significance.

${ }^{9}$ In evaluating the coefficients, we have to remember that it is a negative coefficient on a negative style divergence (i.e. a divergence towards value, losers and small cap stocks) that is indicative of improved performance.
} 
Table 3 Regression results for effectiveness of active management

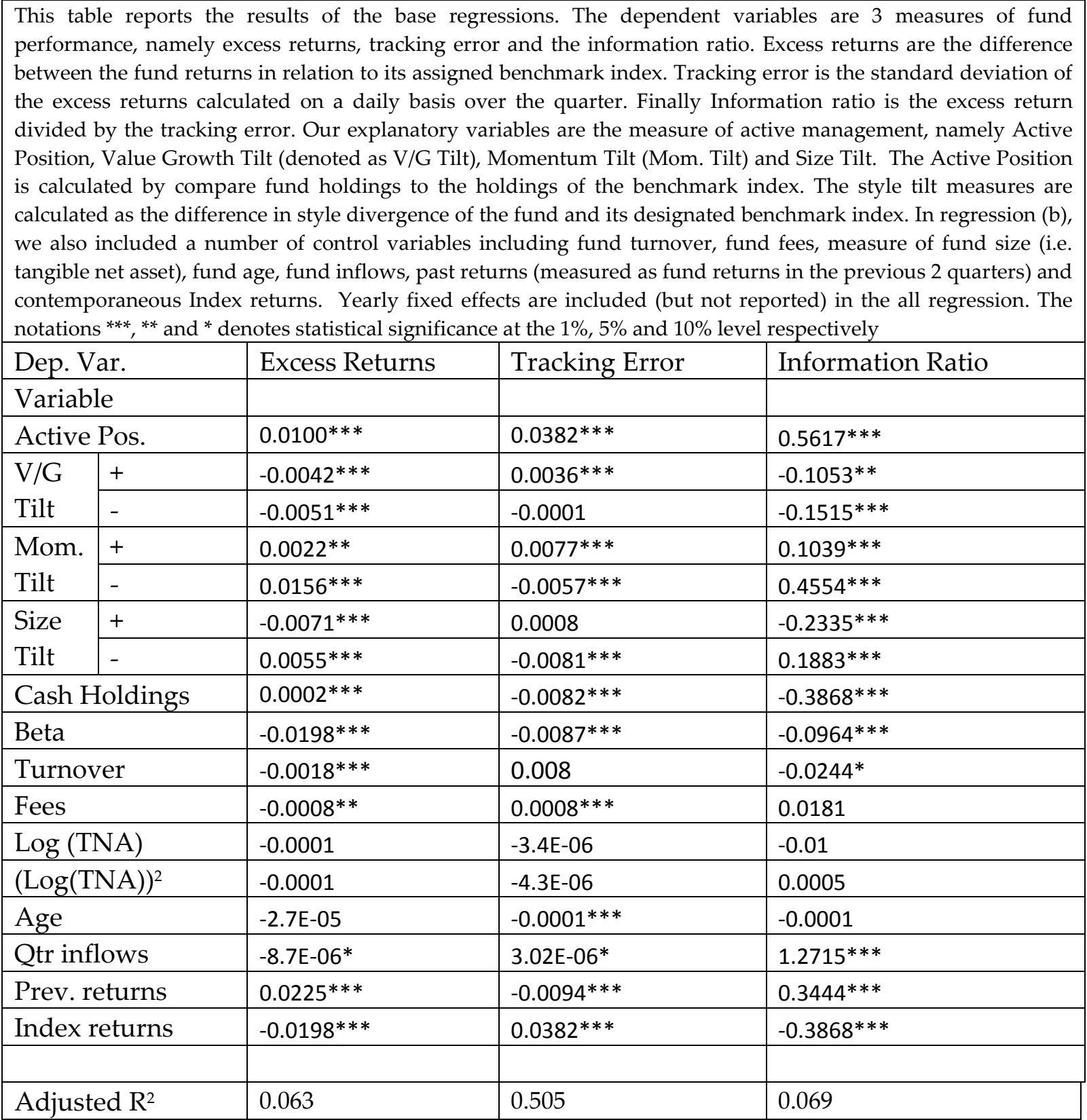

A fund's information ratio may be regarded as a risk-adjusted measure of the consequences of active decisions for fund performance and this provides a useful measure of the ability of fund management. It proves that in all but the cash holdings there is a significant relationship between the active management measure and the information ratio. Active positions, growth and winner divergences all make a positive contribution towards the information ratio of a typical fund. In contrast, the value, loser, large cap and small cap divergences all serve to detract from fund performance. On balance, these findings would appear best for growth managers who are not only the most aggressive manager but whose style divergences would appear must in tune with those that make a positive contribution 
to fund performance. In arriving at this assessment it has to be remembered that all active decisions are judged relative to the fund's benchmark index which themselves vary widely across funds. Therefore, there is not a one-to-one relationship between a particular active decision performing well and stocks with a particular characteristic performing well. We will see more on this when we divide our sample in terms of fund style and when we judge the results of the active decisions against a single index that is representative of the whole market.

Before leaving Table 3, it is worthwhile to pass some observations on the control variables, most of which have significant coefficients. The findings confirm that risk (as measured by a fund's beta), turnover and fees are strong negatives when it comes to choosing managers as they are associated with lower risk-adjusted returns. As all of our performance is measured on a before-fees basis, these findings provide a clear indication that excessive trading is something to avoid and that high fees are more indicative of inferior active skills. It also proves that that the funds that achieve superior performance relative to their benchmark tend to have recent good performance but relatively low cash flows. Finally, the indication is that active managers have most to offer during periods of poor market performance.

\section{Different Market Conditions}

The period covered by our sample was characterised by two periods when the market performed particularly well and two periods when the market went into significant decline. The evidence quoted above suggests that fund performance is significantly influenced by the performance of the market and one would presume that this would also pertain to the success of the active decisions made by fund managers. Hence we repeated our analysis but this time differentiating the impact of the active decisions on performance to that applying during periods of strong and weak market conditions

The findings reported in Table 4 clearly establish the need not only to differentiate between style divergences in both directions but also to incorporate the state of the market conditions into the analysis. It proves that the positive contribution that level of active position makes to performance is evident in both weak and strong markets but it is significantly larger in strong markets. In the light of this, one might expect managers to vary the extent of their active positions in accordance with the market conditions but there is no evidence of them as a group doing this.

The previously identified expertise of managers when diverging from their benchmark portfolio towards growth stocks is shown to exist during both weak and strong markets but is stronger during weak markets. The previous weak association between value divergences and outperformance has been shown to be the result of these divergences having a small negative impact on performance in weak markets and a weak positive impact in strong markets. The managers' ability to add value by their momentum divergences towards winners only contributes to outperformance in weak markets and while the losses that they incur from divergences towards losers holds in both weak and strong market conditions, it is much stronger in weak markets. The overall implication

being that the active momentum decisions have better outcomes during weak markets with 
the bad news being that managers are less active in implementing momentum style tilts during such periods. The size divergences have previously proved to be relatively ineffectual over our whole sample period. By splitting the sample up into periods of weak and strong markets we now see divergences based on size add value, irrespective of the direction of the divergence, during strong markets which is offset by the fact that they detract from value in weak markets. Overall, we have observed that there is fairly wide variation in the performance outcomes of style tilts across different market conditions. Finally, we have the cash holdings which not surprisingly add value during weak markets when cash returns are higher than equity returns. However, the market timing skills of managers comes through more during periods of strong market performance when larger cash holdings are shown to not results in lower excess returns.

Table 4 Regression results for effectiveness of active management in different market conditions.

This table examines the impact and performance of active management under different market conditions. We define "strong" market conditions as the years: 1999, 2003-2006 and 2009. The remaining years of the sample are designated as years of "weak" market conditions. Control variables and Yearly fixed effects are included (but not reported) in all regressions. The notations ${ }^{* * *},{ }^{* *}$ and ${ }^{*}$ denotes statistical significance at the $1 \%, 5 \%$ and $10 \%$ level respectively

\begin{tabular}{|c|c|c|c|c|c|c|c|}
\hline \multirow{2}{*}{\multicolumn{2}{|c|}{$\begin{array}{l}\text { Dep. Var. } \\
\text { Mkt. Conds. }\end{array}$}} & \multicolumn{2}{|c|}{ Excess Return } & \multicolumn{2}{|c|}{ Tracking Error } & \multicolumn{2}{|c|}{ Information Ratio } \\
\hline & & Weak & Strong & Weak & Strong & Weak & Strong \\
\hline \multicolumn{8}{|c|}{ Variable } \\
\hline \multicolumn{2}{|c|}{ Active Pos. } & $0.0071 * * *$ & $0.0134 * * *$ & $0.0418 * * *$ & $0.0339 * * *$ & $0.5633 * * *$ & $0.5818^{* * *}$ \\
\hline \multirow{2}{*}{$\begin{array}{l}\text { V/G } \\
\text { Div. }\end{array}$} & + & $-0.0040 * *$ & $-0.0043 * * *$ & $0.0080 * * *$ & $0.0012 * *$ & -0.0881 & $-0.1181^{* *}$ \\
\hline & - & $-0.0157 * * *$ & 0.0023 & $-0.0030 * * *$ & 0.0010 & $-0.3482 * * *$ & -0.0112 \\
\hline \multirow{2}{*}{$\begin{array}{l}\text { Mom. } \\
\text { Div. }\end{array}$} & + & $0.0086^{* * *}$ & -0.0012 & $0.0101 * * *$ & $0.0064 * * *$ & $0.2921 * * *$ & 0.0024 \\
\hline & - & $0.0232 * * *$ & $0.0098 * * *$ & $-0.0102 * * *$ & $-0.0029 * * *$ & $0.5536 * * *$ & $0.3871 * * *$ \\
\hline \multirow{2}{*}{$\begin{array}{l}\text { Size } \\
\text { Div. }\end{array}$} & + & -0.0034 & $-0.0107 * * *$ & 0.0005 & $0.0023 * * *$ & -0.1747 & $-0.2839 * *$ \\
\hline & - & $0.0153 * * *$ & -0.0032 & $-0.0095 * * *$ & $-0.0072 * * *$ & $0.6295^{* * *}$ & $-0.2114^{* * *}$ \\
\hline \multicolumn{2}{|c|}{ Cash Holdings } & $0.0004 * * *$ & 0.000012 & $0.0003^{* * *}$ & $0.0001 * * *$ & 0.0041 & 0.001234 \\
\hline \multicolumn{2}{|c|}{ Adjusted $\mathrm{R}^{2}$} & \multicolumn{2}{|l|}{0.071} & \multicolumn{2}{|l|}{0.513} & \multicolumn{2}{|l|}{0.055} \\
\hline
\end{tabular}

The previously identified expertise of managers when diverging from their benchmark portfolio towards growth stocks is shown to be restricted to weak markets with it having a negligible impact on performance during strong markets. In contrast, the previous negative relationship between value divergences and performance exists fairly equally weak and strong markets. The managers' ability to add value by their momentum divergences towards winners only contributes to outperformance in weak markets while the losses that they incur from divergences towards losers holds in all market conditions but is strongest in weak markets. The overall implication being that the active momentum decisions have better outcomes during weak markets with the bad news being that managers are less active in implementing momentum style divergences. Our previous finding was that divergences towards both small cap and large cap stocks make a negative 
contribution to investment. Now we find that the negative contribution of large cap divergences is largely restricted to strong markets performance while that of small cap divergences is restricted to weak markets. Overall, we have observed that there is fairly wide variation in the performance outcomes of style tilts across different market conditions. Finally, we have the cash holdings which not surprisingly add value during weak markets when cash returns are higher than equity returns. However, the market timing skills of managers also come through more during periods of strong market performance when larger cash holdings are shown to be neutral in terms of excess returns.

We have previously found that all of the active decisions with the exception of growth and small cap stocks divergences result in an increase of a fund's tracking error. Now we find that that the neutral impact of the growth divergences is restricted to strong markets while that of the large cap stocks is restricted to weak markets. The impact of the active decisions on the information ratio is generally in line with their impact on excess returns. However, this need not necessarily be the case and we do see a few exceptions: on a risk-adjusted basis, value divergences no longer have a significant positive impact on fund performance; in the case of both the active positions and winner divergence during strong markets where a neutral impact on excess returns is translated into a positive impact on the information ratio.

Large or Small Funds?

Bird et al. (2011B) demonstrate that the level of active management within a fund is very much dependent on where the fund is in its life cycle. New smaller funds with little reputation tend to be the most aggressive but this tapers off overtime especially if the fund experiences rapid growth in funds under management. The question we ask here is whether the impact of the various active decisions on performance also changes with the size of the funds. We report in Table 5 the relationship between the four active decisions and investment outcomes for both small and large funds. We find instances of active decisions which bear differing rewards when made by either a large fund or a small fund. The larger funds prove superior with the value and growth divergences while on balance the smaller funds obtain a better outcome with their momentum divergences, specialty when it comes to tilting towards winners. They tend to be about equal in terms of the rewards they obtain from their capitalisation divergences with the larger funds doing the best with their large cap tilts while the smaller funds do better with their small cap tilts. Both small and large funds profit about equally from the active decisions that they make while the larger funds having a small advantage when it comes to decisions relatuing to the level of their cash holdings. Overall, one could conclude that although the larger funds might be less aggressive in their active decisions, they are slightly more successful in terms of the impact that these decisions have their investment performance. As we have come to expect almost all of the active decisions cause an increase in tracking error with the exceptions being the tilts towards growth stocks made by both small and large funds, and the large cap tilts by smaller funds. Finally, the impact of the various active decisions on the information ratio are generally in line with the findings in relation of excess returns and confirm that overall the active decisions made by the larger funds are superior in terms of the impact that they have on investment performance. 
Table 5 Regression results for effectiveness of active management

by various small and large fund managers

\begin{tabular}{|c|c|c|c|c|c|c|c|}
\hline & & & & IIdCKIII 1 & & 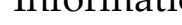 & Ratio \\
\hline Fund & ize. & Small & Large & Small & Large & Small & Large \\
\hline Variab & & & & & & & \\
\hline Active & Pos. & $0.0098 * * *$ & $0.0087 * * *$ & $0.0382 * * *$ & $0.0388 * * *$ & $0.5078 * * *$ & $0.5289 * * *$ \\
\hline $\mathrm{V} / \mathrm{G}$ & + & $-0.0061 * * *$ & -0.0005 & $0.0019 * * *$ & $0.0052 * * *$ & $-0.1687^{* *}$ & 0.0016 \\
\hline Tilt & - & -0.002 & $-0.0108 * * *$ & $0.0014^{*}$ & 0.0001 & -0.0516 & $-0.3476 * * *$ \\
\hline Mom & + & $0.004 * * *$ & 0.0016 & $0.0076 * * *$ & $0.0074 * * *$ & $0.1437 * * *$ & $0.1357^{* *}$ \\
\hline . Tilt & - & $0.0144 * * *$ & $0.015^{* * *}$ & $-0.0059 * * *$ & $-0.005^{* * *}$ & $0.4316^{* * *}$ & $0.4033 * * *$ \\
\hline Size & + & $-0.0117 * * *$ & -0.0046 & -0.0015 & $0.0026^{* *}$ & $-0.313^{* *}$ & -0.1392 \\
\hline Tilt & - & 0.0035 & $0.0057^{*}$ & $-0.0094 * * *$ & $-0.0049 * * *$ & 0.0791 & 0.1768 \\
\hline Cash I & Ioldings & 0.0002 & $0.0002 * *$ & $0.0002 * * *$ & $0.0003 * * *$ & 0.002 & 0.0023 \\
\hline Adjus & ed $R^{2}$ & 0.064 & & 0.507 & & 0.051 & \\
\hline
\end{tabular}

\section{Different Investment Styles}

The next question that we address is whether the link between active decisions and investment outcomes differs across managers pursuing different investment styles. We separate the funds to one of three groups (growth, value or style neutral) on the basis of their allocated benchmark index ${ }^{10}$.

Our findings as reported in Table 6 highlight many key differences between the performance consequences of the active decisions made by the different styles of managers under different market conditions. We have previously shown that the Cremers and Petajisto finding that larger active positions lead to better investment outcomes holds in both weak and strong markets. We now find that it is only the value funds that benefit to a significant extent from the active decisions that they make during both weak and strong markets. The investment performance of the growth funds is improved by their active decisions during period of strong markets conditions whereas such decisions actually detract from performance at times when market conditions are weak. Finally, the style neutral managers benefit from the active positions that they maintain during weak markets but such positions have no effect on performance during times of strong market conditions. Overall, these results highlight that the One observation worth making at this stage is that it is the growth managers who would seem to fare worst with their active position

\footnotetext{
${ }^{10}$ The three sub-groups proved to be of approximately equal size. We ended up with approximately 13,000 quarterly observations for growth funds, 12,000 for value funds and 11,000 for market neutral funds.
} 
decisions who take the largest position in this area. Another being that Cremers and Petajisto finding that large active positions translate into superior performance cannot be generalised across all types of managers and all market conditions.

\section{Table 6 Regression results for effectiveness of active management}

by various investment styles Table 6 presents the results of our analysis of the effectiveness of active management undertaken by various styles of
funds. We classify managers into Growth, Value and Style Neutral style based on the designated benchmark index.
For example, the sample of Value managers contains all the funds that have a value index (i.e. S\&P400 Value,
S\&P500 Value, S\&P600 Value, Russell 1000 Value, Russell 2000 Value and Russell Mid Value) as its designated
benchmark. We define "strong" market conditions as the years: 1999, 2003-2006 and 2009. The remaining years of the
sample are designated as years of "weak" market conditions. Control variables and Yearly fixed effects are included
(but not reported) in all regressions. Yearly fixed effects are included (but not reported) in all regressions. The
notations ${ }^{* * * * *}$ and * denotes statistical significance at the 1\%, 5\% and 10\% level respectively.

\begin{tabular}{|c|c|c|c|c|c|c|c|}
\hline \multirow{2}{*}{\multicolumn{2}{|c|}{$\begin{array}{l}\text { Dep. Var. } \\
\text { Fund Type }\end{array}$}} & \multicolumn{6}{|c|}{ Excess Returns } \\
\hline & & \multicolumn{2}{|c|}{ Growth Manager } & \multicolumn{2}{|c|}{ Value Manager } & \multicolumn{2}{|c|}{ Style Neutral Manager } \\
\hline \multicolumn{2}{|l|}{ Mkt. Conds. } & Poor & Strong & Poor & Strong & Poor & Strong \\
\hline \multicolumn{8}{|l|}{ Variable } \\
\hline Active Pos. & & $-0.0099 *$ & $0.0169 * * *$ & $0.0235 * * *$ & $0.0255^{* * *}$ & $0.0106 * * *$ & 0.0035 \\
\hline \multirow[t]{2}{*}{ V/G Tilt } & + & 0.002 & -0.0016 & $-0.017 * * *$ & $-0.0138 * * *$ & $0.0049 *$ & 0.0033 \\
\hline & - & $-0.0369 * * *$ & -0.0014 & -0.0052 & 0.0038 & $-0.0169 * * *$ & $-0.0053^{*}$ \\
\hline \multirow[t]{2}{*}{ Mom. Tilt } & + & $0.0097^{* * *}$ & $0.0067^{* *}$ & 0.0035 & $-0.0058 * * *$ & $0.012^{* * *}$ & 0.0019 \\
\hline & - & $0.0187^{* * *}$ & $0.0106 * *$ & $0.036^{* * *}$ & $0.009 * * *$ & $0.0118^{* * *}$ & 0.0033 \\
\hline \multirow[t]{2}{*}{ Size Tilt } & + & $0.008^{*}$ & $-0.0075^{* *}$ & 0.0098 & $-0.0265 * * *$ & $-0.0348 * * *$ & 0.0005 \\
\hline & - & $0.0069 * *$ & -0.0004 & $0.0229 * * *$ & -0.0012 & $0.0114 * *$ & $-0.0068^{*}$ \\
\hline \multicolumn{7}{|l|}{ Cash } & $-0.0002 *$ \\
\hline \multicolumn{2}{|c|}{ Adjusted $\mathrm{R}^{2}$} & \multicolumn{2}{|l|}{0.10} & \multicolumn{2}{|l|}{0.17} & \multicolumn{2}{|l|}{0.09} \\
\hline \multicolumn{2}{|l|}{ Dep. Var. } & \multicolumn{6}{|c|}{ Tracking Error } \\
\hline \multicolumn{2}{|l|}{ Fund Type } & \multicolumn{2}{|c|}{ Growth Manager } & \multicolumn{2}{|c|}{ Value Manager } & \multicolumn{2}{|c|}{ Style Neutral Manager } \\
\hline \multicolumn{2}{|l|}{ Mkt. Conds. } & Poor & Strong & Poor & Strong & Poor & Strong \\
\hline \multicolumn{8}{|l|}{ Variable } \\
\hline \multicolumn{2}{|l|}{$\begin{array}{l}\text { Active } \\
\text { Pos. }\end{array}$} & $0.0389 * * *$ & $0.0357 * * *$ & $0.0449 * * *$ & $0.0420 * * *$ & $0.0333 * * *$ & $0.0197 * * *$ \\
\hline \multirow[t]{2}{*}{ V/G Tilt } & + & $0.0039 * * *$ & -0.0010 & $0.0105 * * *$ & $0.0022 * *$ & $0.0131 * * *$ & $0.0047^{* * *}$ \\
\hline & - & $-0.008 * * *$ & -0.0011 & $-0.0054^{* * *}$ & -0.0003 & 0.0014 & $0.0027^{* *}$ \\
\hline \multirow[t]{2}{*}{ Mom. Tilt } & + & $0.0101^{* * *}$ & $0.0033^{* * *}$ & $0.0080 * * *$ & $0.0085^{* * *}$ & $0.0084^{* * *}$ & $0.0053^{* * *}$ \\
\hline & - & $-0.0097 * * *$ & -0.0005 & $-0.0090 * * *$ & $-0.0046^{* * *}$ & $-0.0098 * * *$ & $-0.003 * *$ \\
\hline \multirow[t]{2}{*}{ Size Tilt } & + & 0.0004 & 0.0009 & -0.0022 & $0.0027^{* *}$ & $-0.0079 *$ & $-0.0181 * * *$ \\
\hline & - & $-0.0104 * * *$ & $-0.0066 * * *$ & $-0.0058^{* * *}$ & $-0.0046 * * *$ & $-0.0137 * * *$ & -0.0093 \\
\hline \multicolumn{2}{|l|}{$\begin{array}{l}\text { Cash } \\
\text { Holdings }\end{array}$} & $0.0003 * * *$ & $0.0001^{* *}$ & $0.0003 * * *$ & $0.0002 * * *$ & $0.0004 * * *$ & 0.0000 \\
\hline \multicolumn{2}{|l|}{ Adjusted $\mathrm{R}^{2}$} & \multicolumn{2}{|l|}{0.59} & \multicolumn{2}{|l|}{0.52} & \multicolumn{2}{|l|}{0.45} \\
\hline
\end{tabular}




\begin{tabular}{|c|c|c|c|c|c|c|c|}
\hline \multicolumn{2}{|l|}{ Dep. Var. } & \multicolumn{6}{|c|}{ Information Ratio } \\
\hline \multicolumn{2}{|l|}{ Dep. Var. } & \multicolumn{2}{|c|}{ Growth Manager } & \multicolumn{2}{|c|}{ Value Manager } & \multicolumn{2}{|c|}{ Style Neutral Manager } \\
\hline \multicolumn{2}{|c|}{ Mkt. Conds. } & Poor & Strong & Poor & Strong & Poor & Strong \\
\hline \multicolumn{8}{|l|}{ Variable } \\
\hline \multicolumn{2}{|l|}{$\begin{array}{l}\text { Active } \\
\text { Pos. }\end{array}$} & -0.1988 & $0.2566^{*}$ & $1.092 * * *$ & $1.8839 * * *$ & $0.7175^{* * *}$ & 0.1526 \\
\hline \multirow{2}{*}{ V/G Tilt } & + & -0.0300 & -0.0126 & -0.2281 & $-0.5412 * * *$ & 0.0335 & $0.2804 * * *$ \\
\hline & - & $-0.7899 * * *$ & -0.034 & -0.1272 & 0.1372 & $-0.3354 * *$ & $-0.4508 * * *$ \\
\hline \multirow[t]{2}{*}{ Mom. Tilt } & + & $0.3407 * * *$ & $0.2199 * * *$ & $0.2057^{* *}$ & -0.0797 & $0.3245^{* * *}$ & $0.176^{* *}$ \\
\hline & - & $0.2743 * *$ & $0.3809 * * *$ & $1.0534 * * *$ & $0.351 * * *$ & $0.2818^{*}$ & 0.1584 \\
\hline \multirow[t]{2}{*}{ Size Tilt } & + & $0.3619 * * *$ & -0.1755 & 0.1573 & $-0.659 * * *$ & $-0.6852 *$ & -0.3136 \\
\hline & - & $0.3064 * * *$ & -0.0755 & $0.965 * * *$ & $-0.2715^{* *}$ & 0.2139 & -0.158 \\
\hline \multicolumn{2}{|c|}{\begin{tabular}{l|l} 
Cash & \\
Holdings
\end{tabular}} & 0.0066 & -0.00169 & $0.0155^{* * *}$ & $0.0124 * *$ & $-0.0111 * *$ & 0.0032 \\
\hline \multicolumn{2}{|c|}{ Adjusted $R^{2}$} & \multicolumn{2}{|l|}{0.08} & \multicolumn{2}{|l|}{0.17} & \multicolumn{2}{|l|}{0.07} \\
\hline
\end{tabular}

The value managers skill with their active position decisions is not matched when it comes to their decisions relating to style divergences with there only being one instance of where such divergences result in added value: loser divergences during periods of weak market conditions. In contrast there are five clear instances where their style divergences actually detract from performance and several where they have no significant impact. The value managers lose under all market conditions with the value tilts that they take against their benchmark portfolio whereas any growth tilts that they make are of no consequence. Their momentum divergences have no significant impact on performance when made during weak markets with their one success from the winner tilts they make in strong markets being offset by the failure of their loser tilts. With respect to their style divergences, they again lose from their large cap tilts during strong markets and their small cap tilts during weak markets.

Although far from perfect, the managers following the other two styles are clearly superior to the value managers when it comes to their style divergence decisions. In contrast to the value managers who lose when they more actively pursue their base style, the growth managers add value when they overweight growth stocks in their portfolio during periods when markets are weak while their value tilts have a negligible impact on market performance whem made under all market conditions. The success of the momentum divergences by growth managers is mixed with their winner tilts adding value and their loser tilts detracting from value. The area in which the growth managers are clearly superior is their size divergence decisions where they detract from performance with (like the value managers) their large cap tilts during strong markets and their small cap tilts during weak markets with their success being limited to their large cap tilts during weak markets. 
While one might assign growth managers a bear pass when it comes to style divergences (four winners and three losers), the style neural managers do slightly better with a five-three record. They prove to be the best with their value/growth divergences, adding value with their growth tilts under all market conditions and with their value tilts during weak markets. Momentum divergences prove to be mixed with winner tilts adding value, but losing tilts losing value, during periods of weak markets. Like the other mangers they do not display any particular skills when it comes to size divergences, only adding value with their small cap tilts during strong markets but losing with both large and small cap tilts during weak markets. Our analysis in Table 6 establishes that the active decisions made by style-neutral managers eclipse those of the value managers and are on balance slightly superior to those of the growth managers. However the style-neutral managers are much more conservative in the style divergences that they make and so tend to not exploit their ability to add value as much as the growth managers.

The growth and value managers add value by their decisions relating to cash holdings during periods of weak markets with the cash holding decisions of the style neutral managers having a negligible impact on performance. It is only the value who can use their cash holding decisions to their advantage during periods of weak markets while these decisions made by style neutral managers actually detract from performance during such periods of poor market performance. This all suggest a very clear ranking with value managers being the superior when it comes to cash holding decisions (and so market timers) with the style neutral managers being the worst of the three styles.

As one would expect the clear majority of the active decisions made by managers have a significant positive impact on the tracking error of their fund. However as has been noted previously, this need not necessarily be the case as some active decisions can at the margin have no impact on, or actually reduce, a fund's tracking error. The best example being the growth tilts away from benchmark by the style neutral funds which actually serve to reduce their tracking error, especially when made during periods when market conditions are strong.

It is the combination of excess returns (alpha) with tracking error that provides us with a good measure of the investment expertise of fund management. The analysis of the impact of active decisions on the information ratio confirms the expertise of the value managers in determining both their active positions and cash holdings. However, it also confirms their lack of expertise when making decisions with respect to style divergences where in contrast the growth and style-neutral managers both obtain pass grades ${ }^{11}$.

\section{SEP500}

All the analysis to date has been directed towards identifying the performance implications of the active decisions made by investment managers. Hence we have measured their active decisions relative to a benchmark representative of their investment

\footnotetext{
${ }^{11}$ We have chosen to not report the coefficients for the control variables where we run the separate regressions for the different styles of management. The only significant difference to those reported in Table 3 for the whole sample is that it is only for the growth managers where turnover has a significant negative impact on performance. In the case of the other two styles, the coefficient remains negative but is no longer significant.
} 
style. The role of active fund managers is to exploit persistent inefficiencies in markets and the active decisions are one way of doing this. Another decision made by the manager that has significant implications for the absolute performance of a fund is the original choice of its investment style. From the information contained in Table 1, we observe that the annualised return of the best performing index was 7.96\% (S\&P 400 Value), that for the worst performing index was $-1.09 \%$ (Russell 1000 Growth) while the S\&P 500 index realised an annualised return of $0.87 \%$. This wide variation in performance is very much influenced by the "active decisions" inherent in the various indexes relative to the S\&P 500 . By the use of multi-factor models when measuring fund performance, academics seemed intent of denying managers any credit for their choice of investment style. In order to address this shortcoming, we (again) repeat the analysis but this time assigning all funds the same index (S\&P500) which is representative of the market. In this way we evaluate the performance impact of the combination of the two decisions made by management: the choice of the investment style for the fund and their on-going active decisions when implementing the style. We report the results of our analysis in Table 7 where all active decisions and performance are measured relative to the S\&P 500 for the three styles of management (growth, value and style neutral) and the two types of market conditions (weak and strong) ${ }^{12}$. Our findings provide us with some useful insights as to the relative contributions that the style choice decision and active decisions make to the performance of fund.

After we have incorporated style choice in our analysis, the active positions taken by the value managers (still) make the strongest contribution to performance, particularly during times when market conditions are weak when obviously their style choice contributes to their performance. The style neutral managers remain the second best in making decisions about active positions with it now making a positive contribution to performance whereas previously they only were able to add value during periods of weak market performance. Again our analysis highlights that the incorporation of style choice has made a positive contribution to the value adding capacity of style neutral managers. Finally we have the growth managers who remain the laggards in this area with the active positions inherent in their benchmark actually detracting from performance under all market conditions. The active decisions made by the funds are able to overcome this obstacle in strong markets but not in weal markets.

One of the two tilts embedded in the choice of investment style that adds most to fund performance is a tilt towards value stocks. For value managers, this is a salvation as there divergences in this area have already been shown to detract from their performance. Now taking account of style choice, the combined value tilt of the value funds adds vale in weak markets and has a negligible impact on performance during periods when markets are strong. We have previously seen that value tilts introduced by growth managers were neutral in the impact that they have on performance whereas now we find that as soon as value divergences inherent in investment style that they now add to performance during

\footnotetext{
${ }^{12}$ We exclude the size divergence because of the extreme value calculated when S\&P 500 is used as the benchmark. The S\&P 500 has a large cap bias resulting in the positive size divergences having little crosssectional variation while a significant proportion of the negative style divergences take on very large values.
} 
weak markets and are still neutral during strong markets. Finally, we have the style neutral managers where value divergences due to style choice has improved performance during strong markets but diminished performance during weak marks, thus reversing the impact made by the value divergences decisions made within the style neutral funds. Overall, a value divergence inherent in an investment style has a positive impact on performance reflecting is likely to be a finding not restricted to our data period given the commonly found value premium. This proves to be very important for the value funds given that the divergences that they introduce against their investment style have proved to be very poor investment decisions.

The inherent growth tilts in investment style prove to be much less successful, actually working to the detriment of performance for both the growth and style neutral managers during periods of strong markets while having a negligible effect during weak markets. Again it is the value managers who benefit most from any growth divergences introduced by their style. Previously, we have found that any growth tilts actively introduced into value funds have a negligible impact on performance but now they in combination with ant tilts inherent in style have a positive impact on performance under all market conditions. These findings somewhat reflect that value stocks are on the other side of the value premium and are particularly troublesome for value managers who of course have the strongest bias towards growth stocks and who know lose from this bias during strong markets.

The other inherent tilt in style which works very positive for funds is a tilt towards winners (i.e. strong momentum stocks) which again should come as no surprise given the evidence that on the success of the momentum investment style. Again it is the value funds that have been able to exploit most this advantage as any momentum inherent in their style has added value under all market conditions. The growth and style neutral funds also exploit this advantage but only during periods when market conditions are strong with such inherent tilts due to their style choice have a negligible impact on performance during periods when markets are weak. Not surprisingly, any divergence towards losers stocks inherent in style is far less successful. There are only two instances where these divergences work to advantage of funds: growth and value funds, both during periods of strong markets. In all other cases, the impact of a loser tilt on performance is neutral. Overall, we see that a combined tilt towards winners resulting from both style choice and active decisions results in all types of managers benefiting under all market conditions which is indeed a good finding for investors given the bias of managers of all types of funds to winning stocks. 
Table 7 Regression results for effectiveness of active management where performance is gauged against the S\&P500 Index

Table 7 presents the results of our analysis of the effectiveness of active management undertaken by various styles of funds where fund performance is gauged against S\&P500 Index. The dependent variables are three measures of fund performance, namely excess returns, tracking error and the information ratio. Excess returns are the difference between the fund returns in relation to the S\&P500 index. Tracking error is the standard deviation of the excess returns calculated on a daily basis over the quarter. Finally Information ratio is the excess return divided by the tracking error. We classify managers into Growth, Value and Style Neutral style based on the designated benchmark index. For example, the sample of Value managers contains all the funds that have a value index (i.e. S\&P400 Value, S\&P500 Value, S\&P600 Value, Russell 1000 Value, Russell 2000 Value and Russell Mid Value) as its designated benchmark. We define "strong" market conditions as the years: 1999, 2003-2006 and 2009. The remaining years of the sample are designated as years of "weak" market conditions. Control variables and Yearly fixed effects are included (but not reported) in all regressions. Yearly fixed effects are included (but not reported) in all regressions. The notations ${ }^{* * *}, * *$ and ${ }^{*}$ denotes statistical significance at the $1 \%, 5 \%$ and $10 \%$ level respectively.

\begin{tabular}{|c|c|c|c|c|c|c|c|}
\hline \multirow{3}{*}{\multicolumn{2}{|c|}{$\begin{array}{l}\text { Dep. Var. } \\
\text { Fund Type } \\
\text { Mkt. Conds. }\end{array}$}} & \multicolumn{6}{|c|}{ Excess Returns } \\
\hline & & \multicolumn{2}{|c|}{ Growth Manager } & \multicolumn{2}{|c|}{ Value Manager } & \multicolumn{2}{|c|}{ Style Neutral Manager } \\
\hline & & Poor & Strong & Poor & Strong & Poor & Strong \\
\hline \multicolumn{8}{|c|}{ Variable } \\
\hline $\begin{array}{l}\text { Active } \\
\text { Pos. }\end{array}$ & & $-0.0339 * * *$ & $0.0126^{*}$ & $0.0407 * * *$ & $0.0213 * * *$ & $0.0095 * * *$ & $0.0093 * * *$ \\
\hline $\mathrm{V} / \mathrm{G}$ & + & $0.0333^{* * *}$ & -0.0047 & $0.0169 * * *$ & -0.0017 & 0.0003 & $0.0038 * *$ \\
\hline Tilt & - & $-0.0532 * * *$ & $0.0098 * * *$ & $-0.0397 * * *$ & $-0.0105 * * *$ & $-0.0124^{* * *}$ & -0.001 \\
\hline Mom. & + & $0.0179 * * *$ & $0.0229 * * *$ & $0.0226 * * *$ & $0.0103 * * *$ & $0.0202 * * *$ & $0.0103 * * *$ \\
\hline Tilt & - & $0.0425 * * *$ & $-0.0161 * *$ & $0.0401 * * *$ & $-0.0140 * * *$ & $0.0132 * * *$ & -0.0024 \\
\hline $\begin{array}{l}\text { Cash } \\
\text { Hold. }\end{array}$ & & 0.0001 & -0.0003 & $0.0003^{* *}$ & $-0.0003 * * *$ & $0.0002 *$ & -0.0001 \\
\hline \multicolumn{2}{|c|}{ Adjusted $\mathrm{R}^{2}$} & \multicolumn{2}{|l|}{0.16} & \multicolumn{2}{|l|}{0.11} & \multicolumn{2}{|l|}{0.13} \\
\hline \multicolumn{2}{|c|}{ Dep. Var. } & \multicolumn{6}{|c|}{ Tracking Error } \\
\hline \multicolumn{2}{|c|}{ Fund Type } & \multicolumn{2}{|c|}{ Growth Manager } & \multicolumn{2}{|c|}{ Value Manager } & \multicolumn{2}{|c|}{ Style Neutral Manager } \\
\hline Mkt. C & nds. & Poor & Strong & Poor & Strong & Poor & Strong \\
\hline \multicolumn{8}{|c|}{ Variable } \\
\hline $\begin{array}{l}\text { Active } \\
\text { Pos. }\end{array}$ & & $0.0892 * * *$ & $0.0706 * * *$ & $0.0669 * * *$ & $0.0623 * * *$ & $0.0574 * * *$ & $0.0475 * * *$ \\
\hline $\mathrm{V} / \mathrm{G}$ & + & $-0.0087^{* * *}$ & $-0.0033^{*}$ & $-0.0037 * * *$ & 0.001 & $0.0044 * * *$ & $-0.0035^{* * *}$ \\
\hline Tilt & - & $0.0178^{* * *}$ & -0.0019 & $0.0043 * * *$ & $-0.0055^{* * *}$ & $0.0096 * * *$ & $0.0092 * * *$ \\
\hline \multirow{2}{*}{$\begin{array}{l}\text { Mom. } \\
\text { Tilt }\end{array}$} & + & $0.0031 * * *$ & $0.0058 * * *$ & $0.0099 * * *$ & $0.0043 * * *$ & $0.0066 * * *$ & $0.0055^{* * *}$ \\
\hline & - & $-0.0094 * * *$ & 0.0009 & $-0.0195 * * *$ & $-0.0056 * * *$ & $-0.0159 * * *$ & $-0.0067 * * *$ \\
\hline $\begin{array}{l}\text { Cash } \\
\text { Hold. }\end{array}$ & & $0.0003 * * *$ & -0.0001 & $0.0004 * * *$ & $0.0002 * * *$ & $0.0002 * * *$ & 0.0000 \\
\hline \multicolumn{2}{|c|}{ Adjusted $\mathrm{R}^{2}$} & \multicolumn{2}{|l|}{0.59} & \multicolumn{2}{|l|}{0.50} & \multicolumn{2}{|l|}{0.59} \\
\hline
\end{tabular}




\begin{tabular}{|c|c|c|c|c|c|c|c|}
\hline \multirow{3}{*}{\multicolumn{2}{|c|}{$\begin{array}{l}\text { Dep. Var. } \\
\text { Dep. Var. } \\
\text { Mkt. Conds. }\end{array}$}} & \multicolumn{6}{|c|}{ Information Ratio } \\
\hline & & \multicolumn{2}{|c|}{ Growth Manager } & \multicolumn{2}{|c|}{ Value Manager } & \multicolumn{2}{|c|}{ Style Neutral Manager } \\
\hline & & Poor & Strong & Poor & Strong & Poor & Strong \\
\hline \multicolumn{8}{|c|}{ Variable } \\
\hline $\begin{array}{l}\text { Active } \\
\text { Pos. }\end{array}$ & & $-0.4175 * * *$ & $0.414 * * *$ & $0.9034^{* * *}$ & $0.9514 * * *$ & $0.4994 * * *$ & $0.1984 *$ \\
\hline \multirow{2}{*}{$\begin{array}{l}\text { V/G } \\
\text { Tilt }\end{array}$} & + & $0.6749 * * *$ & 0.0897 & $0.1685^{* * *}$ & 0.0625 & $-0.2342 * * *$ & $0.2681 * * *$ \\
\hline & - & $-1.0203 * * *$ & $0.2341^{* * *}$ & $-1.022 * * *$ & -0.0382 & $-0.5637^{* * *}$ & 0.0418 \\
\hline \multirow{2}{*}{$\begin{array}{l}\text { Mom. } \\
\text { Tilt }\end{array}$} & + & $0.2765^{* * *}$ & $0.459 * * *$ & $0.4613^{* * *}$ & $0.2382 * * *$ & $0.4927^{* * *}$ & $0.4184 * * *$ \\
\hline & - & $0.7446 * * *$ & 0.0923 & $0.7629 * * *$ & -0.0898 & $0.4576 * * *$ & 0.0516 \\
\hline $\begin{array}{l}\text { Cash } \\
\text { Hold. }\end{array}$ & & 0.0056 & -0.0038 & $0.0056 * *$ & -0.0041 & -0.0022 & 0.0013 \\
\hline \multicolumn{2}{|c|}{ Adjusted $\mathrm{R}^{2}$} & \multicolumn{2}{|l|}{0.13} & \multicolumn{2}{|l|}{0.10} & \multicolumn{2}{|l|}{0.073} \\
\hline
\end{tabular}

The style impact is variable with respect to the contribution of cash holdings to performance. During periods when the market is weak, there is an improvement in the impact of cash holdings on performance for style neutral funds but a deterioration for growth funds. When market are performing strongly, now it is the value funds who gain most improvement in terms of the impact that cash holdings have on their performance whereas it is the style neutral funds who suffer a deterioration. After incorporating style into the interpretation of the impact that cash holdings have a performance, it is the value funds who clearly obtain the best outcome. In interpreting these results it must be remembered that there are no cash holdings in the benchmarks so changing benchmarks should really have only a small consequence for the apparent contribution of any management of cash holdings.

There is a clear winner when it comes to choice of style and that is the value funds. Not only does the incorporation of a consideration of style choice point to an improvement of what has already been identified as a strength, active decisions; but it also improves the outcome from all of the style divergences to the extent that what once was found to be a weakness of value managers, is converted to a strength. While the impact of style choice is not as beneficial in terms of its impact on performance for the other styles of funds, it still at the margin would seem to have a small beneficial effect for both growth and style neutral funds.

The overall impact of both style choice and active decisions is perhaps best reflected in the information provided in Table 8. In this table we report on the added value relative to the S\&P500 for all funds and then funds divided by style. The first thing to notice is that the added value due to style chance is about twice that from active decisions and that this is true across both weak and strong markets. It is interesting to note that the added value across all funds due to active decisions of $0.7 \%$ pa is about equivalent to the difference between the fees charged for active management and passive management. Thus the next benefit of active management to investors is about zero suggesting that active managers fully charge for all of their skill advantage (Berk and Green, 2004). The combination of style choice and active decisions results in approximately the same added value for both growth 
and value funds but that added value is delivered in completely different ways. For the growth managers, the added value is more evenly split between style choice and added value with this finding applying across both strong and weak markets. For the value funds, all of the added value comes from the style choice and further all of this added value is restricted to periods when the markets are weak. Fortunately, this is at a time when the value style choice is detracting from performance and so the total effect is that the value funds add value across weak and strong markets. These findings are all consistent with our previous discussion that highlighted both the value adding potential of the value style and the relatively poor active decisions by value managers. Although still positive, the combined added value by the style neutral funds is the weakest of all. The majority of this added value comes during times when markets are weak and reflect the successful active decisions made by style mutual managers ${ }^{13}$.

\begin{tabular}{|c|c|c|c|c|c|c|c|c|c|}
\hline \multicolumn{10}{|c|}{ Table 8 Comparison of fund excess returns against different benchmarks } \\
\hline \multicolumn{10}{|c|}{$\begin{array}{l}\text { Table } 8 \text { presents the results of the analysis of funds style excess performance against several } \\
\text { benchmarks, an assigned index (based on its active position) and the S\&P500 index. As discussed in } \\
\text { an earlier section, we determine each quarter the index that most closely tracks each fund's actual } \\
\text { portfolio (i.e. the index that gives it the smallest active position). As a consequence over the life of } \\
\text { each fund we have a benchmark index assigned each quarter. The index that was chosen in the } \\
\text { greatest number of quarters will be allocated as the fund's benchmark. We reported the average } \\
\text { annualised excess returns of each style of funds against both the S\&P500 Composite index (S\&P500) } \\
\text { and excess returns against the assigned index. In so doing, the difference between the average excess } \\
\text { returns of the S\&P } 500 \text { and the assigned index represents the returns that can be attributed to the } \\
\text { choice of style. }\end{array}$} \\
\hline \multirow{2}{*}{$\begin{array}{l}\text { Performance } \\
\text { relative to } \\
(\% \text { pa): }\end{array}$} & \multicolumn{3}{|c|}{ Full Sample } & \multicolumn{3}{|c|}{ Weak Markets } & \multicolumn{3}{|c|}{ Strong Markets } \\
\hline & $\begin{array}{l}\text { S\&P } \\
500\end{array}$ & $\begin{array}{l}\text { Own } \\
\text { Index }\end{array}$ & $\begin{array}{l}\text { Differ. } \\
\text { (Style) }\end{array}$ & $\begin{array}{l}\text { S\&P } \\
500\end{array}$ & $\begin{array}{l}\text { Own } \\
\text { Index }\end{array}$ & $\begin{array}{l}\text { Differ. } \\
\text { (Style) }\end{array}$ & $\begin{array}{l}\text { S\&P } \\
500\end{array}$ & $\begin{array}{l}\text { Own } \\
\text { Index }\end{array}$ & $\begin{array}{l}\text { Differ. } \\
\text { (Style) }\end{array}$ \\
\hline All Funds & 2.1 & 0.7 & 1.4 & 2.2 & 0.8 & 1.4 & 2.0 & 0.7 & 1.4 \\
\hline Growth & 3.0 & 1.2 & 1.8 & 0.2 & 1.5 & -1.3 & 5.3 & 0.9 & 4.4 \\
\hline Value & 2.7 & 0.1 & 2.6 & 3.0 & -2.7 & 5.7 & 2.4 & 2.4 & 0.0 \\
\hline Neutral & 1.8 & 1.1 & 0.7 & 3.3 & 2.1 & 1.1 & 0.5 & 0.2 & 0.3 \\
\hline
\end{tabular}

A final observation is that the combined impact of style choice and active decisions has some nice implications for tracking error. The typical outcome is that any departures from a fund's benchmark will cause an increase in its tracking error. We have previously found isolated instances when the opposite is the case when considering the active decisions of fund managers. With the introduction of the style choice, the number of the

\footnotetext{
${ }^{13}$ The findings based on the information ratios are in line with those discussed for the excess returns.
} 
instances has grown although being limited to the tracking error impact of value/growth tilts of all three types of managers.

\section{Section 4: Summary Conclusions}

There has been a plethora of papers that analysed the ex-post performance of mutual funds from every possible perspective. Numerous authors have examined the contribution of market timing and cash holding decisions to performance while others have related performance to numerous funds and manager characteristics. One area that has been become the subject of attention in very recent times has been the performance consequences of the stock selection and portfolio construction decisions made by fund managers. In this study we provide the most comprehensive study to date of the impact that active decisions made by the managers of institutional mutual funds have on fund performance. Specifically we look at five distinct active decisions by managers: the extent of their active positions, their style divergences in three dimensions (value/growth, momentum and size) and their cash holdings. We gauge the impact of these decisions on the fund's excess returns, tracking error and information ratio all of which are measured relative to a benchmark index that is reflective of the investment style of the fund.

Our results provide some support for the main findings of Cremers and Petajisto (2009) that it is the more aggressive managers (i.e. those that take the largest active positions) who realise the best performance. We establish that the positive contribution that the funds' active positions make to performance is strongest for value funds, twice as strong markets than it is in weak markets and is shared equally by small and large funds. Most importantly, we establish that the finding is not universal in that active positions do not work style neutral managers in weak markets and actually work to the disadvantage of clients of growth markets in weak markets.

The performance of the funds with their style divergences relative to their benchmark paints a fairly sorry tale. The two areas where the funds can clearly add value is from the divergences they make towards growth and winning stocks which fortunately are common tilts that many managers build into their portfolios. However, they actually detract vale from the tilts that they introduce in all other areas: large, small, value and losers. Of course, none of these findings are universal with the growth and winning tilts only working to improve the performance of funds in periods when markets are weak while large cap tilts only work to the disadvantage of funds during periods when markets are weak and small cap tilts only work to the disadvantage of funds in periods when markets are strong. Further, it is only the larger funds that benefit from the growth tilts while the smaller funds benefit most from the winner tilts. The different styles of funds also fare quite differently with respect to the success of their style divergences. The big losers are the value funds where there is not a single instance of a style divergence that adds value under either strong or weak markets. The growth and the style neutral meet with relatively more success with their style divergences with both doing particularly well with their growth and winner tilts made during periods when markets are weak. 
In summary, the value managers are particularly good in the active positions that they and also with the management of their cash holdings but these are offset by the extremely poor investment performance of the style divergences that they build into their portfolios. In contrast, the growth and style neutral managers fare much worse with their active positions and cash holdings but do get some rewards from the style divergences that they introduce in their portfolios towards growth stocks and winners.

Consistent with what has become tradition the bulk of the analysis conducted in this study has been based on a comparison between a fund's performance to that of a benchmark that reflects its style. As such we are measuring one important area of a fund's proficiency: the ability to add value by the active decisions that it makes in the implementation of its style. However, there is another key area that is ignored by this approach to assessing performance: the choice of an investment style and the process for implementing that style. We establish the importance of the choice of investment style by a fund as a major determinant of its performance and extend our analysis to evaluate the combined contribution of the style choice and the active management to performance. Our major finding being that value managers who were previously inferior to the growth and style neutral managers in making style tilts are now at least their equals. This is consistent with the value style being the best performer over our sample period which is something that the value managers have been able to enhance by their active positions but detract from due to their style divergences.

The major contribution of this paper is to provide insights into where management succeeds and fails in converting its active decisions into superior performance. In a practical sense this should prove useful in directing investors as to where to look when seeking to identify superior managers. The use of the modelling to date is limited by the fact that it provides on average results and does not tell us anything precise about any particular fund. For example, the fact that in aggregate growth managers are particularly good at identifying the losing stocks which are about to mean-revert in performance does that not mean that all growth managers have this skill. An obvious extension of this work is to develop it further so that it can more directly be used in our search for the Holy Grail, how to better be able to identify those managers who will produce good performance in the future.

\section{References}

Baker, K., J. Haslem and D. Smith (2009), "Performance and Characteristics of Actively Managed Institutional Equity Mutual Funds", Journal of Investing, Vol. 18, p. 27 44 .

Bird, R., L. Casavecchia, P.Pellizzari and P. Woolley (2011A), “The Impact on the Pricing Process of Costly Active Management and Performance Chasing Clients", Journal of Economic Integration and Coordination, https://springerlink3.metapress.com/content/5161j68716512w13/resourcesecured/?target=fulltext.pdf\&sid=m0pz4t45is5a3v550prto3iy\&sh=www.springerlink.com 
Bird, R. P.Pellizzari, P. Woolley and D. Yeung (2011B), “Active Bets by Mutual Funds" Paul Woolley Centre University of Technology Sydney Working Paper

Brown, K., and W. Harlow (2001), "Mutual Fund Styles”, The Journal of Finance, Vol. 43 , pp. $373-399$.

Busse, J., A. Goyal, and A. Wahal (2010), "Performance and Persistence in Institutional Management", The Journal of Finance, Vol. 65, pp. 765 - 790.

Carhart, M. (1997), “On Persistence in Mutual Fund Performance” Journal of Finance, 52 (March 1997), pp. 57-82.

Chevalier, J., and G. Ellison (1999), The Journal of Finance, Vol. 54, pp. 875 - 899.

Cremers, M., and A Petajisto (2009), How Active is Your Fund Manager? A New Measure that Predicts Performance, Review of Financial Studies, Vol. 22, pp. 3329 - 3365.

Fama, E., and French, K (1993). "Common Risk Factors in the Returns on Stocks and Bonds." Journal of Financial Economics, pp. 3-56.

French, K. (2008), "The Costs of Active Management", The Journal of Finance, Vol. 63, pp. $1537-1573$.

Golec, J., (1996), “The Effects of Mutual Fund managers' characteristics on their Portfolio Performance, Risk and Fees", Financial Services Review, Vol. 5., pp. 133 - 148.

Goyal, A., and S Wahal (2008), "the Selection and Termination of Investment Management Firms by Plan Sponsors", The Journal of Finance, Vol. 63, pp. 1805 - 1847

Jensen, M. (1968), “The Performance of Mutual Funds in the Period 1945-1964." Journal of Finance, Vol. 23, pp. 389-416.

Karoui, A., and I. Meier (2009), "Performance and Characteristics of Mutual Fund Starts", European Journal of Finance, Vol. 15. pp. 487 - 509.

Petajisto, A (2010), "Active Share and Mutual Fund Performance", Stern School New York Working Paper

Sharpe, W. (1966), “Mutual Fund Performance.” Journal of Business, pp. 119-138.

Treynor, J. (1985), “How to Rate Management of Investment Funds." Harvard Business Review, Vol. 43 (, pp. 63-73.

Vayanos, D., and P. Woolley (2008), “An Institutional Theory of Momentum and Reversals", Paul Woolley Centre London School of Economics Working Paper

Wermers. R. (2010), “A Matter of Style: The Causes and Consequence of Style Divergence in Institutional Portfolios", Smith School University of Marylands Working Paper

Xan, X. (2006), “The Determinants and Implications of mutual Fund cash Holdings: Theory and Evidence", Financial Management, pp. 67 - 91. 
Supplementary Table Regression results for effectiveness of active management for funds of different level of active investment

\begin{tabular}{|c|c|c|c|c|c|c|c|}
\hline \multicolumn{8}{|c|}{$\begin{array}{l}\text { This table examines the impact and performance of active management by managers of different levels of } \\
\text { "activeness". We sort the managers by their level of active bets. The managers that falls within the lowest tercile } \\
\text { are defined as "low active bet managers. On the other hand, funds that fall within the highest terciles are } \\
\text { regarded as the most active manager. Control variables and Yearly fixed effects are included (but not reported) in } \\
\text { all regressions. The notations }{ }^{* * *, * *} \text { and * denotes statistical significance at the } 1 \%, 5 \% \text { and } 10 \% \text { level respectively }\end{array}$} \\
\hline \multicolumn{2}{|c|}{ Dep. Var. } & \multicolumn{2}{|c|}{ Excess Return } & \multicolumn{2}{|c|}{ Tracking Error } & \multicolumn{2}{|c|}{ Information Ratio } \\
\hline \multicolumn{2}{|c|}{ Mkt. Conds. } & $\begin{array}{l}\text { Low } \\
\text { Active } \\
\text { Bet } \\
\text { Tercile }\end{array}$ & $\begin{array}{l}\text { High } \\
\text { Active Bet } \\
\text { Tercile }\end{array}$ & $\begin{array}{l}\text { Low } \\
\text { Active } \\
\text { Bet } \\
\text { Tercile }\end{array}$ & $\begin{array}{l}\text { High } \\
\text { Active Bet } \\
\text { Tercile }\end{array}$ & $\begin{array}{l}\text { Low } \\
\text { Active } \\
\text { Bet } \\
\text { Tercile }\end{array}$ & $\begin{array}{l}\text { High } \\
\text { Active } \\
\text { Bet } \\
\text { Tercile }\end{array}$ \\
\hline \multicolumn{8}{|l|}{ Variable } \\
\hline \multicolumn{2}{|c|}{ Active Pos. } & $0.0151 * * *$ & $0.0074 * *$ & $0.0274 * * *$ & $0.03076^{* * *}$ & $0.9675^{* * *}$ & $0.6536 * * *$ \\
\hline \multirow[t]{2}{*}{ V/G Tilt } & + & $-0.0133 * * *$ & 0.0006 & 0.0002 & $0.0036^{* * *}$ & $-0.3832 * * *$ & 0.0136 \\
\hline & - & -0.0052 & $-0.0047 * *$ & $0.0042 * * *$ & $-0.0017 * * *$ & $-0.319 * *$ & -0.1113 \\
\hline \multirow{2}{*}{$\begin{array}{l}\text { Mom. } \\
\text { Tilt }\end{array}$} & + & 0.0002 & $0.0061 * * *$ & $0.0086 * * *$ & $0.0076 * *$ & 0.1103 & $0.1686 * * *$ \\
\hline & - & $0.0108 * * *$ & $0.0149 * * *$ & $-0.0044 * * *$ & $-0.0059 * * *$ & $0.3637^{* * *}$ & $0.3889 * * *$ \\
\hline \multirow[t]{2}{*}{ Size Tilt } & + & $-0.0367 * * *$ & -0.00189 & $-0.0096 * * *$ & 0.0001 & $-1.2893 * * *$ & 0.0644 \\
\hline & - & -0.0062 & $0.006184 * * *$ & $-0.0033^{*}$ & $-0.0080 * * *$ & $-0.4974 * *$ & $0.1730 * * *$ \\
\hline \multicolumn{2}{|c|}{ Cash Holdings } & -0.0001 & $0.0005^{* * *}$ & $0.0002 * * *$ & $0.0003 * * *$ & -0.0062 & $0.0080 * *$ \\
\hline \multicolumn{2}{|c|}{ Adjusted $\mathrm{R}^{2}$} & \multicolumn{2}{|l|}{0.07} & \multicolumn{2}{|l|}{0.51} & \multicolumn{2}{|l|}{0.05} \\
\hline
\end{tabular}

